\title{
Aziridine- and Azetidine-Pd Catalytic Combinations. Synthesis and Evaluation of the Ligand Ring Size Impact on Suzuki-Miyaura Reaction Issues
}

\author{
Hamza Boufroura, Benjamin Large, Talia Bsaibess, Serge Perato, Vincent Terrasson, \\ Anne Gaucher and Damien Prim* \\ Institut Lavoisier de Versailles, UMR CNRS 8180, Université de Versailles Saint-Quentin-en-Yvelines, \\ 45 Avenue des Etats-Unis, 78035 Versailles CEDEX, France; hamza.boufroura@uvsq.fr (H.B.); \\ benjamin.large@uvsq.fr (B.L.); talia.bsaibess@uvsq.fr (T.B.); serge.perato@u-psud.fr (S.P.); \\ vincent.terrasson@hotmail.fr (V.T.); anne.gaucher@uvsq.fr (A.G.) \\ * Correspondence: damien.prim@uvsq.fr; Tel.: +33-013-925-4455 \\ Academic Editor: Ioannis D. Kostas \\ Received: 29 November 2016; Accepted: 10 January 2017; Published: 13 January 2017
}

\begin{abstract}
The synthesis of new vicinal diamines based on aziridine and azetidine cores as well as the comparison of their catalytic activities as ligand in the Suzuki-Miyaura coupling reaction are described in this communication. The synthesis of three- and four-membered ring heterocycles substituted by a methylamine pendant arm is detailed from the parent nitrile derivatives. Complexation to palladium under various conditions has been examined affording vicinal diamines or amine-imidate complexes. The efficiency of four new catalytic systems is compared in the preparation of variously substituted biaryls. Aziridine- and azetidine-based catalytic systems allowed Suzuki-Miyaura reactions from aryl halides including chlorides with catalytic loadings until $0.001 \%$ at temperatures ranging from $100{ }^{\circ} \mathrm{C}$ to r.t. The evolution of the Pd-metallacycle ring strain moving from azetidine to aziridine in combination with a methylamine or an imidate pendant arm impacted the Suzuki-Miyaura reaction issue.
\end{abstract}

Keywords: aziridine; azetidine; vicinal diamine; imidate; ligand; Suzuki-Miyaura coupling

\section{Introduction}

The Suzuki-Miyaura reaction is "an easy way for C-C bonding" [1]. This statement is especially worthwhile in modern organic synthesis. Indeed, the advent of the Suzuki-Miyaura reaction represents a critical step in this field. This reaction has become for decades a major methodological tool available to chemists to build molecular architectures especially based on a biaryl scaffold. The biaryl motif can be found in numerous natural products, agrochemicals, drugs, polymers, ligands and thus triggered the attention of the scientific community for a wide range of applications [2-9]. If the formation of a biphenyl motif belongs nowadays to a textbook knowledge, the past decade has witnessed spectacular innovations and improvements such as ligandless transformations [10], supported or nanostructured catalytic systems [11-13], performing additives [14,15], neat and/or aqueous conditions [2,13,15], MW activations [10] for example.

Although the presence of a ligand is not strictly mandatory, increase of selectivity, the use of poorly reactive chlorides, room temperature conditions remains challenging and usually requires a ligand $[11,13,15,16]$. Additionally, preformed and geometrically constrained catalytic systems appears as crucial features beneficial to a catalytic activity enhancement $[8,17]$. If phosphorus-based catalytic systems dominated this area during the last decades, nitrogen-containing ligands revealed recently useful and appear as a pertinent alternative. In this context, ligands incorporating pyridyl-based scaffolds as well as combinations of pyridines linked to flexible alkylamine arms or rigid 
cycloalkylamines such as piperidines have been successfully developed in recent years [17-23]. In this communication, we describe new ligands based on strained aza-heterocycles such as aziridines and azetidines. We focused on two strategies using these small aza-heterocycles. The first one involves a combination of these small aza-heterocycles and a flexible methylamine side chain while the second requires a more rigid pendant arm based on an imidate moiety (Figure 1).

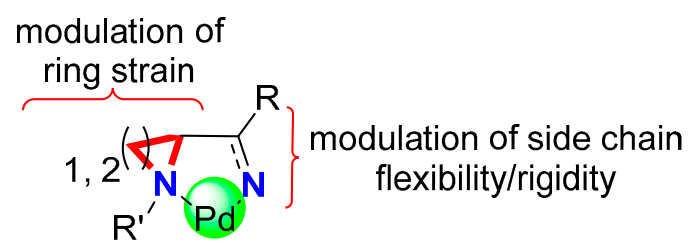

Figure 1. Aziridine- and azetidine-based catalytic systems. Modulation of ring and side chain strain.

We expect the modulation of the ring and side chain strains to impact the catalytic properties of these new ligands families. The abilities of the latter to promote couplings especially involving aromatic chlorides will be examined. In addition, room temperature conditions will further be prioritized in the context of the synthesis of variously substituted biphenyls.

\section{Results and Discussion}

\subsection{Synthesis of Catalytic System}

\subsubsection{Synthesis of Ligand Precursors}

Cyanoazetidine 1 and cyanoaziridine 2 have been easily obtained in two and three steps respectively starting from commercially available reactants as reported earlier [24,25]. The further step was to prepare vicinal diamines 3 and 4 . Both diamines were obtained using a two-step sequence, first an addition of phenylmagnesium bromide followed by a reduction with sodium borohydride. According to recent literature [26-28] reduction afforded a 9/1 ratio of diastereomers. In the absence of X-ray data, a relative stereochemistry can only be hypothesized. In good agreement with literature data [26-28], the assumed anti selectivity, might results from a hydride attack on the less strained Re face of the imine moiety leading as depicted in Scheme 1 . The proposed chelate model could result either from an intramolecular hydrogen bond between the tertiary amine and imino moieties or from the formation of a five-membered Mg-chelate after addition of the Grignard reagent. The probable major anti diastereomer was in each case isolated after silica gel chromatography purification in $56 \%$ and $69 \%$ yields respectively (Scheme 1 ).

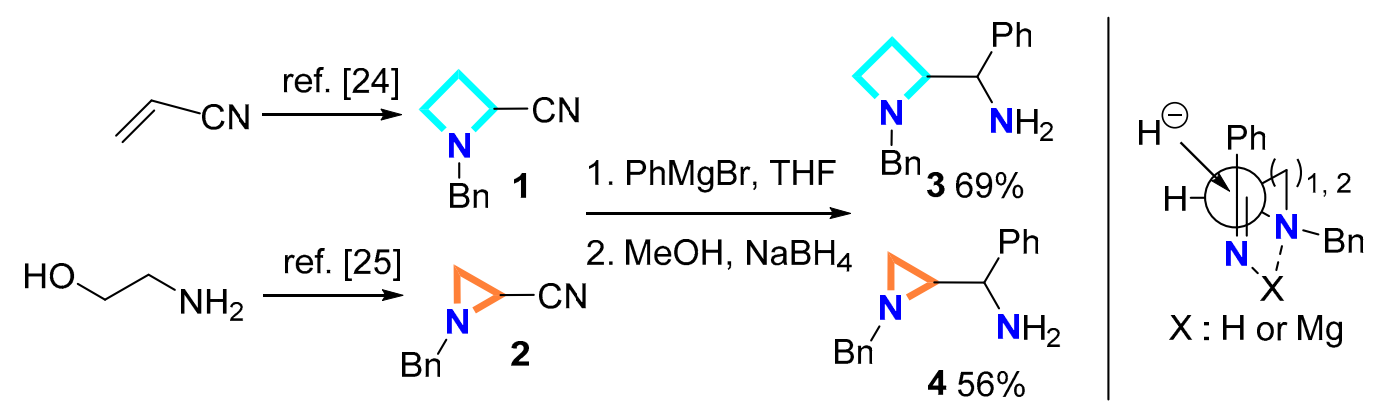

Scheme 1. Synthesis of aziridine and azetidine ligand precursors. 


\subsubsection{Synthesis of Pd Complexes}

The next step was the preparation of Pd complexes starting from both nitrile and diamine precursors.

- Synthesis of vicinaldiamine-based Pd complexes

For this purpose, vicinal diamines 3 and 4 were reacted with $\mathrm{Na}_{2} \mathrm{PdCl}_{4}$ in freshly distilled $\mathrm{MeOH}$ for $20 \mathrm{~h}$ at room temperature. Expected complexes A and $\mathbf{B}$ were easily obtained after filtration and successive washings with cold $\mathrm{MeOH}$, ether and pentane in $94 \%$ and $83 \%$ yields respectively (Scheme 2).
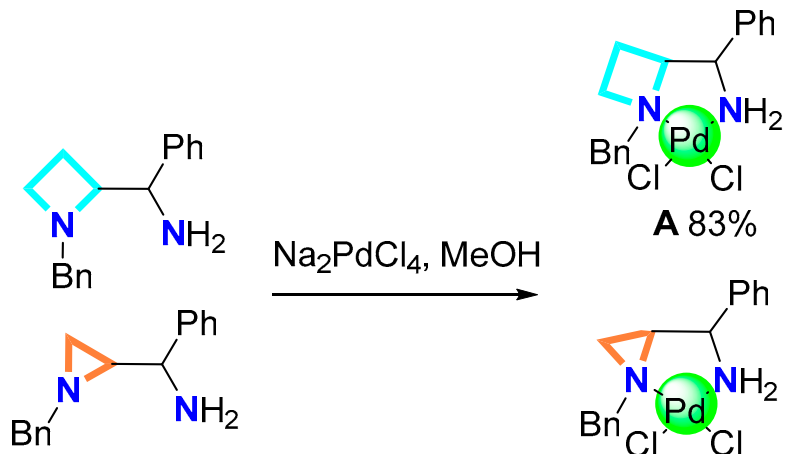

A $83 \%$

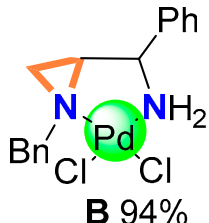

Scheme 2. Preparation of diamine-Pd complexes A and B.

- Synthesis of heterocycle/amidate-based Pd complexes

Amidate-Pd complexes were prepared under similar conditions and isolated by simple filtration and washings as shown in Scheme 3. Dual complexation of the nitrile group and the heterocyclic nitrogen atom to palladium in $\mathrm{MeOH}$ allowed the activation of the nitrile group and the formation of the imidate fragment through nucleophilic addition of one equivalent of methanol moiety. Bidendate complexes $\mathbf{C}$ and $\mathbf{D}$ display characteristic chemical shifts in ${ }^{1} \mathrm{H}$ and ${ }^{13} \mathrm{C}$ NMR corresponding to the presence of an imidate fragment as shown in Scheme 3. Methoxy groups appear at 3.87 and $3.65 \mathrm{ppm}$ in ${ }^{1} \mathrm{H}$ NMR and the sp $\mathrm{p}^{2}$ carbon appear at 175.3 and $177.3 \mathrm{ppm}$ in ${ }^{13} \mathrm{C}$ NMR. Both novel complexes were obtained in $70 \%$ and $63 \%$ yields respectively (Scheme 3 ).

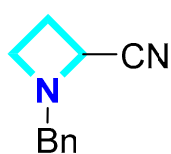

$\stackrel{\mathrm{Na}_{2} \mathrm{PdCl}_{4}, \mathrm{MeOH}}{\longrightarrow}$<smiles>N#CC1CN1Br</smiles>
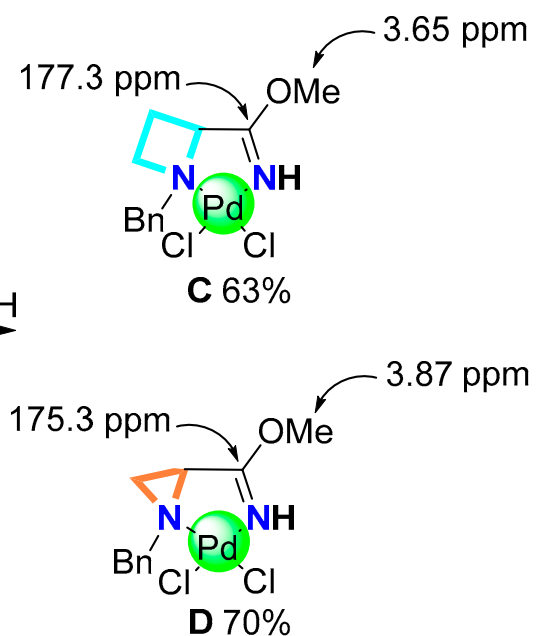

Scheme 3. Preparation of amine/imidate-Pd complexes $\mathbf{C}$ and $\mathbf{D}$ and characteristic chemical shifts in ${ }^{1} \mathrm{H}$ and ${ }^{13} \mathrm{C}$ NMR spectra. 
Within these series, complexes appeared more stable than the corresponding ligands. Especially the aziridine 3 displays averaged stability, we assume to arise from ring opening without careful storage under inert conditions. Complexes display high stability for months. No modification of aspect, ${ }^{1} \mathrm{H}$ NMR spectra or catalytic activities was noticed.

\subsection{Evaluation of Catalytic Properties}

Catalytic properties of complexes A, B, C and D were next evaluated. The coupling between 4-bromonitrobenzene and 4-tolylboronic acid was chosen as the model coupling reaction (Scheme 4). Gratifyingly, running the reaction at room temperature for $10 \mathrm{~h}$, using $1 \%$ of catalytic loading and base/solvent combination $\left(\mathrm{Cs}_{2} \mathrm{CO}_{3}\right.$ and $\left.\mathrm{DMF} / \mathrm{H}_{2} \mathrm{O}\right)$ as already reported for benzhydrylamines [20-24], allowed us to identify 4-nitro- $4^{\prime}$-methyl biphenyl 5 in the crude material ${ }^{1} \mathrm{H}$ NMR spectra. Various conversions were observed ranging from $10 \%$ to $50 \%$ evidencing that our catalytic systems were able to trigger Suzuki-Miyaura coupling at room temperature.
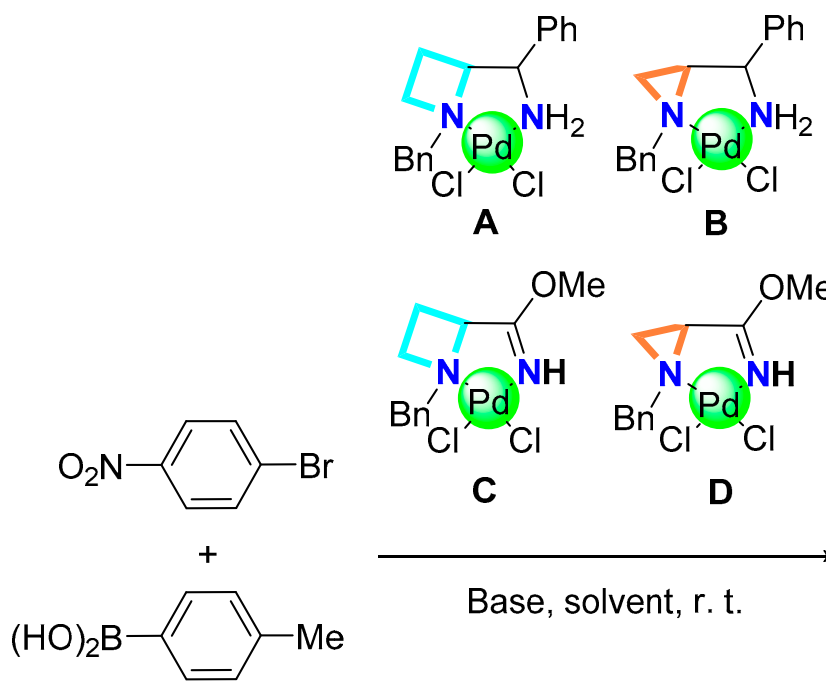

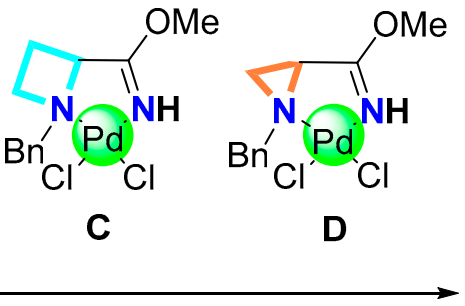

Base, solvent, r. t.

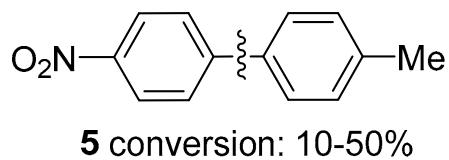

Scheme 4. Catalysts A-D applied to a model Suzuki reaction.

- Optimisation of catalytic conditions

The next step was to adjust the base/solvent combination. Among several base $\left(\mathrm{Na}_{2} \mathrm{CO}_{3}\right.$, $\mathrm{NaHCO}_{3}, \mathrm{~K}_{3} \mathrm{PO}_{4}, \mathrm{CsF}$ ) and solvent (THF, dioxane, toluene/ethanol $/ \mathrm{H}_{2} \mathrm{O}$ ) combination tests, $\mathrm{Cs}_{2} \mathrm{CO}_{3}$ as the base and $\mathrm{DMF} / \mathrm{H}_{2} \mathrm{O}(9 / 1)$ as the solvent, gave the best conversions.

All catalytic systems were further evaluated and compared each other as shown in Figure 2. In the context of the synthesis of biphenyl derivative 5, iodo-, bromo- and chloro-precursors were independently reacted with 4-tolylboronic acid using $\mathbf{A}, \mathbf{B}, \mathbf{C}$ and $\mathbf{D}$ catalysts, $\mathrm{Cs}_{2} \mathrm{CO}_{3}$ as the base and $\mathrm{DMF} / \mathrm{H}_{2} \mathrm{O}(9 / 1)$ as the solvent at various catalytic loadings. Results obtained with $1 \%$ and $0.1 \%$ of catalyst loading at room temperature are compared in Figure $2 \mathrm{a}, \mathrm{b}$ respectively and results obtained with $0.01 \%$ and $0.001 \%$ of catalyst loading at $100{ }^{\circ} \mathrm{C}$ are compared in Figure $2 \mathrm{c}$, d respectively.

Figure 2a shows obtained results when using $1 \%$ of catalyst loading for $16 \mathrm{~h}$ at room temperature. Iodides readily react affording the expected biphenyl motif in $93 \%$ to quantitative Yields whatever the catalyst A, B, C or D. The use of bromides and chlorides allowed us to clearly differentiate the efficiency of both catalyst families. Indeed, diamine-based catalysts $\mathbf{A}$ and $\mathbf{B}$ and amine/imidate catalysts $\mathbf{C}$ and $\mathbf{D}$ behaved differently. Best results were obtained using the more strained catalysts $\mathbf{C}$ and $\mathbf{D}$. If transformation of arylchloride using $\mathbf{D}$ as the catalyst led to $41 \%$ in $16 \mathrm{~h}$ at room temperature, an extended reaction time to $48 \mathrm{~h}$ at room temperature allowed us to reach $94 \%$ yield. 
A similar trend was observed with $0.1 \%$ catalytic loading for $24 \mathrm{~h}$ at room temperature (Figure $2 \mathrm{~b}$ ). Amine/imidate complexes $\mathbf{C}$ and $\mathbf{D}$ revealed superior to diamine complexes $\mathbf{A}$ and $\mathbf{B}$. Aryliodides were transformed up to quantitative yields at room temperature. An expected decrease of catalytic activity is observed when moving to bromides and chloride. At this loading, complex $\mathbf{D}$ that displays an enhanced ring strain and a more rigid side chain led to best results. Again, an extended reaction time to $48 \mathrm{~h}$ improved the yield of biphenyl 5\% to $58 \%$ at room temperature.

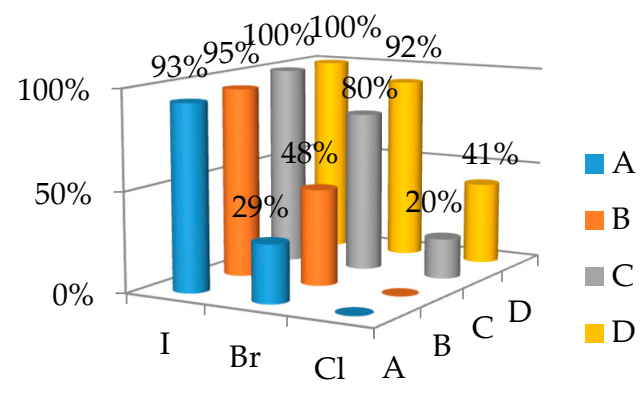

(a)

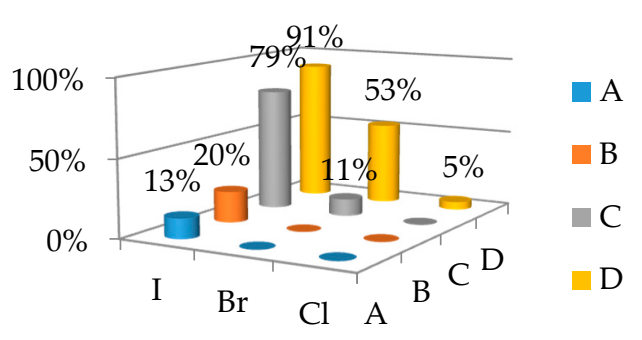

(c)

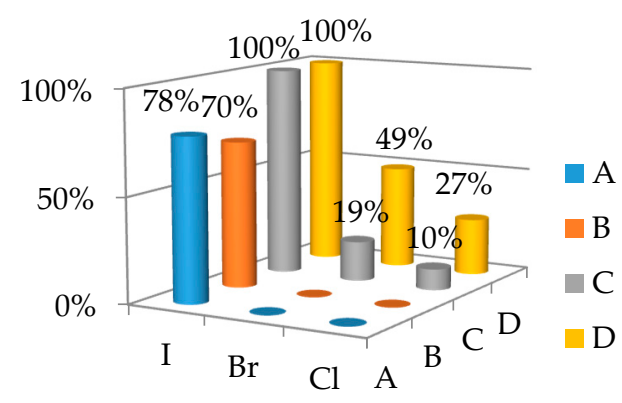

(b)

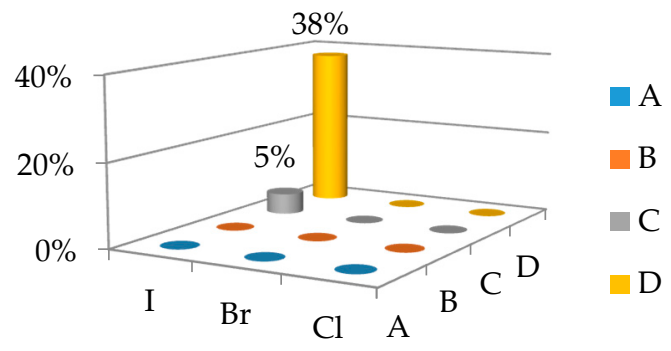

(d)

Figure 2. Comparison of catalytic system: (a) Catalytic loading 1\%, 16h, r.t.; (b) Catalytic loading $0.1 \%$, 24 h, r.t.; (c) Catalytic loading $0.01 \%, 24 \mathrm{~h}, 100^{\circ} \mathrm{C}$; (d) Catalytic loading $0.001 \%, 24 \mathrm{~h}, 100{ }^{\circ} \mathrm{C}$.

At lower catalytic loadings such as $0.01 \%$ and $0.001 \%$ (Figure $2 \mathrm{c}, \mathrm{d}$ ) reactions were run at $100{ }^{\circ} \mathrm{C}$. Again both complex families were compared and the amine/imidate $\mathbf{C}$ and $\mathbf{D}$ were found superior to the diamine complexes A and B. Again combination of ring and side chain enhanced strain in catalyst $\mathbf{D}$ revealed beneficial to catalytic activity. Indeed, the use of D at $0.01 \%$, allowed reaching $91 \%$ yield for aryliodides and 53\% for bromides. In contrast, chlorides exhibit only poor conversion. At $0.001 \%$ at $100{ }^{\circ} \mathrm{C}$ only aryl iodides react affording the expected biphenyl motif in $38 \%$ yield. In contrast, using bromides and chlorides analogues showed no reaction.

In fact, complex D was found superior to all others at room temperature until $0.1 \%$ loading and at $100{ }^{\circ} \mathrm{C}$ at lower loadings. Better results obtained using complex $\mathbf{D}$, may result from the joint presence of an enhanced ring strain and a more rigid side chain which both likely play a crucial role in the transmetalation step of the catalytic cycle and the final product releasing step.

- Application to various substrates

Complex D was next evaluated in several Suzuki-Miyaura reactions. Table 1 gathers results obtained using various combinations of electronic effects for both aryl halides and boronic acids. As shown, chlorides bearing electron withdrawing groups are transformed in fair to high yields at room temperature using catalytic loadings ranging from $1 \%$ to $0.1 \%$ (entries $1-6,9,12-13$ ). Reactions using boronic acids substituted by electron withdrawing groups such as $\mathrm{NO}_{2}$-phenyl, $\mathrm{CH}_{3} \mathrm{CO}$-phenyl or sterically hindered substituents required the use of bromides in order to obtain the desired biphenyl with fair to excellent yields (entries 10-11, 14-16). Phenyl halides substituted by electron donating 
groups such as MeO-phenyl and HO-phenyl (entries 17-21) also required the use of bromides at catalytic loadings from $0.1 \%$ to $1 \%$ and / or increase of temperature from room temperature to $100{ }^{\circ} \mathrm{C}$ respectively. Finally, 2,2'-biphenyl (entries $22-24)$ could be obtained in high yields ( $89 \%-90 \%)$ at $100{ }^{\circ} \mathrm{C}$ using either chlorides or bromides at $0.1 \%$ and $0.01 \%$ catalytic loading.

Table 1. Synthesis of biaryls using catalyst $\mathrm{D}, \mathrm{Cs}_{2} \mathrm{CO}_{3}$ as the base and $\mathrm{DMF} / \mathrm{H}_{2} \mathrm{O}(9 / 1)$ as the solvent.

\begin{tabular}{|c|c|c|c|c|c|c|}
\hline Entry & $\begin{array}{c}\text { Halide } \\
\text { Fragment }\end{array}$ & $\begin{array}{c}\text { Boronic Acid } \\
\text { Fragment }\end{array}$ & Halide & Cat. Load. & Conditions & $\begin{array}{c}\text { Yield } \\
(\%)\end{array}$ \\
\hline 1 & & & $\mathrm{Cl}$ & $0.1 \%$ & r.t., $24 \mathrm{~h}$ & 28 \\
\hline 2 & & & $\mathrm{Cl}$ & $1 \%$ & r.t., $18 \mathrm{~h}$ & 88 \\
\hline 3 & & & $\mathrm{Cl}$ & $0.1 \%$ & r.t., $24 \mathrm{~h}$ & 21 \\
\hline 4 & & & $\mathrm{Cl}$ & $1 \%$ & r.t., $24 \mathrm{~h}$ & 69 [29] \\
\hline 5 & & & $\mathrm{Cl}$ & $0.1 \%$ & r.t., $24 \mathrm{~h}$ & 21 \\
\hline 6 & & & $\mathrm{Cl}$ & $1 \%$ & r.t., $24 \mathrm{~h}$ & 60 \\
\hline 7 & & & $\mathrm{Br}$ & $0.01 \%$ & $100{ }^{\circ} \mathrm{C}, 24 \mathrm{~h}$ & 89 \\
\hline 8 & & & $\mathrm{Br}$ & $0.1 \%$ & $100^{\circ} \mathrm{C}, 6 \mathrm{~h}$ & $93^{\mathrm{a}}[30]$ \\
\hline 9 & & & $\mathrm{Cl}$ & $1 \%$ & r.t., $24 \mathrm{~h}$ & 30 \\
\hline 10 & & & $\mathrm{Br}$ & $0.1 \%$ & r.t., $24 \mathrm{~h}$ & 43 \\
\hline 11 & & & $\mathrm{Br}$ & $1 \%$ & r.t., $24 \mathrm{~h}$ & 61 \\
\hline 12 & & & $\mathrm{Cl}$ & $0.1 \%$ & r.t., $24 \mathrm{~h}$ & 16 \\
\hline 13 & & & $\mathrm{Cl}$ & $1 \%$ & r.t., $24 \mathrm{~h}$ & 45 \\
\hline 14 & & & $\mathrm{Br}$ & $0.1 \%$ & r.t., $24 \mathrm{~h}$ & 58 \\
\hline 15 & & & $\mathrm{Br}$ & $0.1 \%$ & r.t., $24 \mathrm{~h}$ & 52 \\
\hline 16 & & & $\mathrm{Br}$ & $1 \%$ & r.t., $24 \mathrm{~h}$ & $81[31]$ \\
\hline 17 & & & $\mathrm{Cl}$ & $1 \%$ & $100^{\circ} \mathrm{C}, 18 \mathrm{~h}$ & 32 \\
\hline 18 & & & $\mathrm{Br}$ & $1 \%$ & r.t., $24 \mathrm{~h}$ & 39 [32] \\
\hline 19 & & & $\mathrm{Cl}$ & $1 \%$ & $100{ }^{\circ} \mathrm{C}, 18 \mathrm{~h}$ & 25 \\
\hline 20 & $\mathrm{Me}$ & & $\mathrm{Br}$ & $1 \%$ & $100^{\circ} \mathrm{C}, 18 \mathrm{~h}$ & $57[33]$ \\
\hline 21 & & & $\mathrm{Br}$ & $0.1 \%$ & r.t., $18 \mathrm{~h}$ & 45 \\
\hline 22 & & & $\mathrm{Cl}$ & $1 \%$ & r.t., $24 \mathrm{~h}$ & 30 \\
\hline 23 & & & $\mathrm{Cl}$ & $0.1 \%$ & $100^{\circ} \mathrm{C}, 6 \mathrm{~h}$ & 89 \\
\hline 24 & & & $\mathrm{Br}$ & $0.01 \%$ & $100{ }^{\circ} \mathrm{C}, 24 \mathrm{~h}$ & 90 \\
\hline
\end{tabular}

a A similar yield of $87 \%$ has been obtained using an analogue of catalyst $\mathrm{C}$ under similar reaction conditions [27].

\section{Materials and Methods}

\subsection{Materials}

Unless otherwise noted, all starting materials were obtained from commercial suppliers and used without purification. Petroleum ether was distilled under Argon. NMR spectra were recorded on a $300 \mathrm{MHz}$ and $200 \mathrm{MHz}$ Brucker spectrometers (Bruker BioSpin GmbH, Rheinstetten, Germany). Chemical shifts were reported in ppm relative to the residual solvent peak (7.27 ppm for $\mathrm{CHCl}_{3}$ ) for ${ }^{1} \mathrm{H}$ spectra and $\left(77.00 \mathrm{ppm}\right.$ for $\left.\mathrm{CDCl}_{3}\right)$ for ${ }^{13} \mathrm{C}$ spectra. High Resolution Mass spectroscopy data were recorded on an Autospec Ultima (Waters/Micromass) device (Waters, Gyancourt, France,) with a resolution of $5000 \mathrm{RP}$ at $5 \%$. Thin-layer chromatography (TLC) was carried out on aluminium sheets precoated with silica gel 60 F254. Column chromatography separations were performed using silica gel (0.040-0.060 mm). ( $N$-benzyl)-2-cyanoazetidine 1 and ( $N$-benzyl)-2-cyanoaziridine 2 have been prepared according to references $[24,25]$. 


\subsection{Methods}

\subsubsection{General Procedure for Addition/Reduction Sequence}

The phenylmagnesium chlorde $(2 \mathrm{mmol})$ was added to a solution of 2-cyanoderivative $\mathbf{1}$ or $\mathbf{2}$ $(1 \mathrm{mmol})$ in dry THF $(10 \mathrm{~mL})$ at $0{ }^{\circ} \mathrm{C}$ under argon. After stirring for $20 \mathrm{~min}, \mathrm{MeOH}(10 \mathrm{~mL})$ and $\mathrm{NaBH}_{4}$ $(1.2 \mathrm{mmol})$ were successively added. After a further $1 \mathrm{~h}$, the reaction was quenched with saturated aqueous $\mathrm{NH}_{4} \mathrm{Cl}$ solution $(5 \mathrm{~mL})$, and extracted with EtOAc $(3 \times 10 \mathrm{~mL})$. The combined organic extracts were washed with brine, dried with magnesium sulfate and concentrated under reduced pressure. Amines 3 and 4 were purified by silica gel column chromatography using cyclohexane/Et ${ }_{2} \mathrm{O} 1: 1$ as the eluant.

\subsubsection{General Complexation Procedure}

To a stirred solution of ligand 1-4 $(0.25 \mathrm{mmol})$ in $5 \mathrm{~mL}$ of freshly distilled $\mathrm{MeOH}$ was added $\mathrm{Na}_{2} \mathrm{PdCl}_{4}$ (74 mg, $\left.0.25 \mathrm{mmol}\right)$. The mixture was stirred at room temperature for 1 to $16 \mathrm{~h}$ and filtered over a celite pad. The filtrate was removed by evaporation under vacuum. The residue was then purified over silica gel pad eluting first with cyclohexane/EtOAc 7:3 to remove traces of free ligand, then with EtOAc for ligands $\mathbf{3}$ and $\mathbf{4}$ and with AcOEt/MeOH 95:5 for ligands $\mathbf{1}$ and $\mathbf{2}$.

\subsubsection{General Suzuki Coupling Procedure}

To a stirred solution of aromatic halide $(0.5 \mathrm{mmol})$, boronic acid $(0.6 \mathrm{mmol})$ and $\mathrm{Cs}_{2} \mathrm{CO}_{3}(407 \mathrm{mg}$, $1.25 \mathrm{mmol}$ ) in $1 \mathrm{~mL}$ of $\mathrm{DMF} / \mathrm{H}_{2} \mathrm{O}$ (95:5) was added the palladium complex as a solid or in solution in $\mathrm{DMF} / \mathrm{H}_{2} \mathrm{O}$ (95:5). The mixture was stirred at room temperature or $100{ }^{\circ} \mathrm{C}$ (refer to Table 1). $10 \mathrm{~mL}$ of EtOAc and $10 \mathrm{~mL}$ of water were then added and the aqueous phase was extracted with EtOAc $(3 \times 5 \mathrm{~mL})$. The combined organic layers were dried $\left(\mathrm{MgSO}_{4}\right)$, filtered and concentrated under vacuum, the crude product was purified by flash chromatography on silica gel to give the biaryl product.

\section{Conclusions}

Two new families of ligands based on an aziridine and azetidine core have been developed. Starting from the parent aziridine- and azetidine-nitriles, vicinal diamines and amine/imidate palladium complexes were obtained respectively using a nucleophilic addition/reduction-complexation sequence or a direct complexation in methanol. Evaluation and comparison of the catalytic activities of four complexes are described. The amine/imidate family $\mathbf{C}$ and $\mathbf{D}$ was found superior to the diamine analogues family $\mathbf{A}$ and $\mathbf{B}$. Within the amine/imidate family best results were achieved using complex $\mathbf{D}$ that combines both enhanced ring strain and side chain rigidity. The aziridine-imidate complex $\mathbf{D}$ proved to be efficient for the synthesis of various substituted biphenyls. Catalyst $\mathbf{D}$ allowed iodides to react at $100{ }^{\circ} \mathrm{C}$ and catalytic loadings as low as $0.001 \%$. In addition, bromides are able to be used as partners in couplings at $100{ }^{\circ} \mathrm{C}$ and loadings of $0.01 \%$. Finally, $\mathbf{D}$ catalyzes the reaction of chlorides at room temperature using catalytic loadings ranging from $1 \%$ to $0.1 \%$.

Supplementary Materials: The following are available online at www.mdpi.com/2073-4344/7/1/27/s1, experimental procedures for the preparation of precursors, catalytic systems and Suzuki couplings as well as analytical data for new compounds.

Acknowledgments: University of Versailles St Quentin, MENRT-France, ANR (ANR-11-BS07-030-01), IDEX (ANR-10-IDEX-0003-02) and LabEx CHARMMMAT (ANR-11-LABEX-0039) are gratefully acknowledged for financial supports and grants (HB, BL, SP, VT).

Author Contributions: H.B., B.L., T.B., S.P. and V.T. conceived and performed the experiments; A.G. and D.P. analyzed the data and wrote the paper.

Conflicts of Interest: The authors declare no conflict of interest. 


\section{References}

1. Suzuki, A. Cross-coupling reactions of organoboranes: An easy way to construct C-C bonds (Nobel Lecture). Angew. Chem. Int. Ed. 2011, 50, 6722-6737. [CrossRef] [PubMed]

2. Chatterjee, A.; Ward, T.R. Recent advances in the palladium catalyzed Suzuki-Miyaura cross-coupling reaction in water. Catal. Lett. 2016. [CrossRef]

3. Zhang, D.; Wang, Q. Palladium catalyzed asymmetric Suzuki-Miyaura coupling reactions to axially chiral birayl compounds: Chiral ligands and recent advances. Coord. Chem. Rev. 2015, 286, 1-16. [CrossRef]

4. Maluenda, I.; Navarro, O. Recent developments in the Suzuki-Miyaura reaction: 2010-2014. Molécules 2015, 20, 7528-7557. [CrossRef] [PubMed]

5. Han, F.-Y. Transition-metal-catalyzed Suzuki-Miyaura cross-coupling reactions: A remarkable advance from palladium to nickel catalysts. Chem. Soc. Rev. 2013, 42, 5270-5298. [CrossRef] [PubMed]

6. Kumar, A.; Kumar Rao, G.; Kumar, S.; Singh, A.K. Organosulphur and related ligands in Suzuki-Miyaura C-C coupling. Dalton Trans. 2013, 42, 5200-5223. [CrossRef] [PubMed]

7. Rossi, R.; Bellina, F.; Lessi, M. Selective palladium-catalyzed Suzuki-Miyaura reactions of polyhalogenated heteroarenes. Adv. Synth. Catal. 2012, 354, 1181-1255. [CrossRef]

8. Li, H.; Seechurn, C.C.C.J.; Colacot, T.J. Development of preformed Pd catalysts for cross-coupling reactions, beyond the 2010 Nobel prize. ACS Catal. 2012, 2, 1147-1164. [CrossRef]

9. Liu, S.-Y.; Li, H.-Y.; Shi, M.-M.; Jiang, H.; Hu, X.-L.; Li, W.-Q.; Fu, L.; Chen, H.-Z. Pd/C as a clean and effective heterogeneous catalyst for $\mathrm{C}-\mathrm{C}$ couplings toward highly pure semiconducting polymers. Macromolecules 2012, 45, 9004-9009. [CrossRef]

10. Arvela, R.K.; Leadbeater, N.E.; Sangi, M.S.; Williams, V.A.; Granados, P.; Singer, R.D. A reassessment of the transition-metal free Suzuki-type coupling methodology. J. Org. Chem. 2005, 70, 161-168. [CrossRef] [PubMed]

11. Jawale, D.V.; Gravel, E.; Boudet, C.; Shah, N.; Geertsen, V.; Li, H.; Namboothiri, I.N.N.; Doris, E. Room temperature Suzuki coupling of aryl iodides, bromides and chlorides using a heterogeneous carbon nanotube-palladium nanohybrid catalyst. Catal. Sci. Technol. 2015, 5, 2388-2392. [CrossRef]

12. Hong, M.C.; Choi, M.C.; Chang, Y.W.; Lee, Y.; Kim, J.; Rhee, H. Palladium nanoparticles on thermoresponsive hydrogels and their application as recyclable Suzuki-Miyaura coupling reaction catalysts in water. Adv. Synth. Catal. 2012, 354, 1257-1263. [CrossRef]

13. Maegawa, T.; Kitamura, Y.; Sako, S.; Udzu, T.; Sakurai, A.; Tanaka, A.; Kobayashi, Y.; Endo, K.; Bora, U.; Kurita, T.; et al. Heterogeneous Pd/C-catalyzed ligand free, room-temperature Suzuki-Miyaura coupling reactions in aqueous media. Chem Eur. J. 2007, 13, 5937-5943. [CrossRef] [PubMed]

14. Liu, D.-X.; Gong, W.-J.; Li, H.-X.; Gao, J.; Li, F.-L.; Lang, J.-P. Palladium(II)-catalyzed Suzuki-Miyaura reactions of arylboronic acid with aryl halide in water in the presence of 4-(benzylthio)- $N, N, N$ trimethylbenzenammonium chloride. Tetrahedron 2014, 70, 3385-3389. [CrossRef]

15. Lipshutz, B.H.; Petersen, T.B.; Abela, A.R. Room-temperature Suzuki-Miyaura couplings in water facilitated by non-ionic amphiphiles. Org. Lett. 2008, 10, 1333-1336. [CrossRef] [PubMed]

16. Tang, Y.; Zeng, Y.; Hu, Q.; Huang, F.; Jin, L.; Mo, W.; Sun, N.; Hu, B.; Shen, Z.; Hu, X.; et al. Efficient catalyst for both Suzuki and Heck cross-coupling reactions: Synthesis and catalytic behaviour of geometry-constrained iminopyridylpalladium chlorides. Adv. Synth. Catal. 2016, 358, 2642-2651. [CrossRef]

17. Yang, J.; Liu, S.; Zheng, J.-F.; Zhou, J. Room-temperature Suzuki-Miyaura coupling of heteroaryl chlorides and tosylates. Eur. J. Org. Chem. 2012, 6248-6259. [CrossRef]

18. Najera, C.; Gil-Molto, J.; Karlström, S. Suzuki-Miyaura and related cross-coupling in aqueous solvents catalyzed by di(2-pyridyl)methylamine-palladium dichloride complexes. Adv. Synth. Catal. 2004, 346, 1798-1811. [CrossRef]

19. Puget, B.; Roblin, J.-P.; Prim, D.; Troin, Y. New 2-(2-pyridyl)piperidines: Synthesis, complexation of palladium and catalytic activity in Suzuki reaction. Tetrahedron Lett. 2008, 49, 1706-1709. [CrossRef]

20. Terrasson, V.; Prim, D.; Marrot, J. N-Heterocyclic benzhydrylamines as New N,N-Bidentate ligands in palladium complexes: Synthesis, characterization and catalytic activity. Eur. J. Inorg. Chem. 2008, 2739-2745. [CrossRef] 
21. Gunawan, M.-A.; Qiao, C.; Abrunhosa-Thomas, I.; Puget, B.; Roblin, J.-P.; Prim, D.; Troin, Y. Simple pyridylmethylamines: Efficient and robust $N, N$-ligands for Suzuki-Miyaura coupling reactions. Tetrahedron Lett. 2010, 51, 5392-5394. [CrossRef]

22. Grach, G.; Pieters, G.; Dinut, A.; Terrasson, V.; Medimagh, R.; Bridoux, A.; Razafimahaleo, V.; Gaucher, A.; Marque, S.; Marrot, J.; et al. N-Heterocyclic pyridylmethylamines: Synthesis, complexation, molecular structure, and application to asymmetric Suzuki-Miyaura and oxidative coupling reactions. Organometallics 2011, 30, 4074-4086. [CrossRef]

23. Requet, A.; Yalgin, H.; Prim, D. Convenient and rapid strategies towards 6-(hetero)arylpyridylmethylamines. Tetrahedron Lett. 2015, 56, 1378-1382. [CrossRef]

24. Couty, T.; David, O.; Larmanjat, B.; Marrot, J. Strained azetidinium ylides: New reagents for cyclopropanation. J. Org. Chem. 2007, 72, 1058-1061. [CrossRef] [PubMed]

25. Ayi, A.I.; Guedj, R. Reaction of hydrogen fluoride in pyridine solution with cis-cyano-2-and cis-amido-2aziridines. Preparation of $\beta$-fluoro- $\alpha$-amino acids and esters by means of acidic hydrolysis and alcoholysis of $\beta$-fluoro- $\alpha$-amino nitriles and/or $\beta$-fluoro- $\alpha$-amino acid amides. J. Chem. Soc. Perkin Trans. 1983, 2045-2051. [CrossRef]

26. Keller, L.; Vargas-Sanchez, M.; Prim, D.; Couty, F.; Evano, G.; Marrot, J. Azetidines as ligands in the palladium (II) complexes series. J. Organomet. Chem. 2005, 690, 2306-2311. [CrossRef]

27. Pieters, G.; Puget, B.; Terrasson, V.; Roblin, J.-P.; Gaucher, A.; Marque, S.; Prim, D.; Troin, Y. On the robustness of methylamines-Pd catalytic systemsin the Suzuki reaction: Compromise examples between synthesis and catalysis. Rev. Chim. (Bucarest) 2010, 61, 825-827.

28. Besev, M.; Engman, L. Diastereocontrol by a hydroxyl auxiliary in the synthesis of pyrrolidines via radical cyclization. Org. Lett. 2002, 4, 3023-3025. [CrossRef] [PubMed]

29. Kataoka, N.; Shelby, Q.; Stambuli, J.P.; Hartwig, J.F. Air stable, sterically hindered ferrocenyl dialkylphosphines for palladium-catalyzed $\mathrm{C}-\mathrm{C}, \mathrm{C}-\mathrm{N}$, and $\mathrm{C}-\mathrm{O}$ bond-forming cross-couplings. J. Org. Chem. 2002, 67, 5553-5566. [CrossRef] [PubMed]

30. Yanagisawa, S.; Sudo, T.; Noyori, R.; Itami, K. Direct C-H Arylation of (Hetero)arenes with Aryl Iodides via Rhodium Catalysis. J. Am. Chem. Soc. 2006, 128, 11748-11749. [CrossRef] [PubMed]

31. Tao, B.; Boykin, D.W. Simple amine/Pd(OAc) $)_{2}$-catalyzed Suzuki coupling reactions of aryl bromides under mild aerobic conditions. J. Org. Chem. 2004, 69, 4330-4335. [CrossRef] [PubMed]

32. Mino, T.; Shirae, Y.; Saito, T.; Sakamoto, M.; Fujita, T. Palladium-catalyzed Sonogashira and Hiyama reactions using phosphine-free hydrazone ligands. J. Org. Chem. 2006, 71, 9499-9502. [CrossRef] [PubMed]

33. Mendes Da Silva, J.F.; Perez, A.F.Y.; Pinto de Almeida, N. An efficient and new protocol for phosphine-free Suzuki coupling reaction using palladium-encapsulated and air-stable MIDA boronates in an aqueous medium. RSC Adv. 2014, 4, 28148-28155. [CrossRef]

(C) 2017 by the authors; licensee MDPI, Basel, Switzerland. This article is an open access article distributed under the terms and conditions of the Creative Commons Attribution (CC-BY) license (http://creativecommons.org/licenses/by/4.0/). 